\title{
Modelling colour changes during the caramelisation reaction
}

\author{
Mafalda A.C. Quintas, Teresa R.S. Brandão, Cristina L.M. Silva* \\ Escola Superior de Biotecnologia, Universidade Católica Portuguesa, R. Dr. António Bernardino de Almeida, 4200-072 Porto, Portugal
}

Keywords: Caramelisation reaction; Colour kinetics; Sucrose degradation and hydroxymethylfurfural (HMF) formation

\begin{abstract}
Sucrose solutions, with concentrations near or superior to saturation, present high potentialities for the candy and pastry industries. The development of colour in a neutral and highly concentrated sucrose solution $(16.32 \%(\mathrm{w} / \mathrm{w})$ water content) subjected to isothermal heat treatment (in the $100-160^{\circ} \mathrm{C}$ range) was investigated. Under such conditions, sucrose degrades through caramelisation and 5hydroxymethylfurfural (HMF) is formed. Colour development was monitored through lightness/darkening $\left(L / L_{0}\right)$ and total colour difference $\left(\mathrm{TCD}_{\mathrm{H}}\right)$ changes during reaction course. Kinetic behaviour was mathematically described using modified Gompertz equations. The effect of temperature on the reaction was described by an Arrhenius type dependency. Colour development and sucrose degradation kinetic parameters were compared and similar lag phases were found. However, the same was not observed for reactions rate, indicating that not only sucrose degradation contributes to colour development. To investigate the colour development/HMF content relationship, a fractional conversion and a power law models where successfully proposed to express, respectively, $L / L_{0}$ and TCD ${ }_{\mathrm{H}}$ dependence on HMF content.
\end{abstract}

\section{Introduction}

Highly concentrated sucrose solutions (sugar syrups) are extensively used in pastry and confectionery products. These syrups are prepared by heating a mixture of sugar and water (3:1) to high temperatures in order to dissolve the sugar and evaporate water, producing supersaturated solutions. During this process sucrose can degrade, through the caramelisation reaction, leading to non-enzymatic browning and thus colour changes. Besides contributing to the visual aspect and flavour of the final product, colour changes can be used to control reaction's extension.

Colour is an important attribute in food products, since it is perceived immediately by the consumer. It can also be a measurement of reactions extension in food products, since formed and/or degraded compounds may contribute to a specific coloration (Francis, 1995). Colour can be assessed either by a sensory panel or using analytical instrumentation. A typical example is the profuse use of absorbance readings in the $400-460 \mathrm{~nm}$ to evaluate brown pigments formation during non-enzymatic browning. However, tristimulus colorimetry has become a popular technique and equipment, since it mimics human colour perception without any prior sample preparation. It is based on the existence of three main elements: the light source (illuminant), the object of the study (which reflects or transmits light) and the observer (which receives the signal and interprets into units related to how the human eye "sees" colour) (Francis, 1995; Hutchings, 1994). The interpretation of such human colour perception, lead to the development of several colour scales. Under white light, any colour can be defined by a mixture of red, blue and green primaries. The International Commission on Illumination (CIE) defined a parallel interpretation by setting unreal primaries $X Y Z$, which

\footnotetext{
Corresponding author. Tel.: +351 2255800 58; fax: +3512250903 51.E-mail address: clsilva@esb.ucp.pt (C.L.M. Silva).
} 


\section{Nomenclature}

a colour space coordinate (degree of greenness/ redness)

$\alpha, \beta$ and $\chi$ Gompertz model parameters

$b \quad$ colour space coordinate (degree of blueness/yellowness)

$A, B$ power-law model parameters

$C \quad$ any colour parameter (i.e. $L, a, b$ or other)

$\hat{C} \quad$ any colour parameter estimated by the model

$E_{\mathrm{a}} \quad$ activation energy $\left(\mathrm{J} \mathrm{mol}^{-1}\right)$

$E_{\mathrm{a}_{k_{\max }}}$ activation energy for the $k_{\max }$ parameter $\left(\mathrm{J} \mathrm{mol}^{-1}\right)$

$E_{\mathrm{a} \lambda} \quad$ activation energy for the $\lambda$ parameter $\left(\mathrm{J} \mathrm{mol}^{-1}\right)$

$F_{(\mathrm{P}, \mathrm{N}-\mathrm{P}, 0.05)}$ upper $5 \%$ of the quantile for Fisher distribution (P and N-P degrees of freedom)

[HMF] HMF content $\left(g_{\mathrm{HMF}} / g_{\text {solution }}\right)$

$k$ fractional conversion model parameter ( $g_{\text {solution }} /$ $g_{\text {HMF }}$ )

$k_{\max } \quad$ maximum reaction rate $\left(\mathrm{min}^{-1}\right)$

$L \quad$ colour space coordinate (lightness)

$\lambda \quad$ lag time (min)
MSE mean square error

$N \quad$ number of experimental data points

$p \quad$ kinetic parameter

$P \quad$ number of estimated parameters

$R \quad$ universal gas constant $\left(8.314 \mathrm{~J} \mathrm{~mol}^{-1} \mathrm{~K}^{-1}\right)$

$R^{2} \quad$ coefficient of determination

SE standard error

SHW standardised half with (\%)

$t \quad$ time (min)

$T$ temperature $\left({ }^{\circ} \mathrm{C}\right.$ or $\left.\mathrm{K}\right)$

TCD total colour difference

$v$ parameters derivative vector

$\left(V^{\mathrm{T}} V\right)^{-1}$ parameter variance-covariance matrix

\section{Subscripts}

$\mathrm{H} \quad$ refers to Hunter colour space coordinates

0 refers to colour parameter at initial time

ref refers to parameter at reference temperature

eq refers to property at equilibrium can be mathematically converted into more easily interpreted and linear colour scales: the Hunter $L a b$ and the CIE Lab (Hutchings, 1994) colour spaces. Both these scales are similar and represent a 3-dimension rectangular space based on the opponent-colours theory, where $L-$ represents the lightness axis and measures how light/dark is the sample, $a$ - measures the greenness/redness of the sample and $b$ - represents products' blueness/yellowness (Hutchings, 1994).

Colour changes in a food product due to process are commonly evaluated through changes in the scale parameters $(L, a$ and $b)$ and/or through the Total Colour Difference (Eq. (1)) parameter, which evaluates the overall colour difference of a processed sample compared to a reference one (indicated by the index 0 in the following expression):

$\mathrm{TCD}=\sqrt{\left(L-L_{0}\right)^{2}+\left(a-a_{0}\right)^{2}+\left(b-b_{0}\right)^{2}}$

Non-enzymatic browning is the general denomination of darkening of a food product due to any reaction not owed to enzymatic activity. Although this includes several reaction types, such as lipid oxidation or ascorbic acid degradation, non-enzymatic browning is manly associated with carbohydrate degradation reactions, such as the Maillard and caramelisation reactions (BeMiller \& Whistler, 1996). Colour changes due to Maillard reaction are extensively described in literature (e.g. are Baisier \& Labuza, 1992; Bell, White, \& Chen, 1998; Bruijn, Stuijs, \& Bout-Dierderen, 1999; Buera, Chirifie, Resnik, \& Lozano, 1987b; Imming, Buczys, Lehnberger, \& Bliesener, 1996; Lievonen, Laaksonen, \& Roos, 1998; Reyes, Poocharoen, \& Wrols- tad, 1982; Schebor, Buera, Karel, \& Chirife, 1999). On the other hand, caramelisation related colour development has been less studied (Buera, Chirifie, Resnik, \& Lozano, 1987a; Buera, Chirifie, Resnik, \& Wetzler, 1987; Cammerer, Wedzicha, \& Kroh, 1999).

Caramelisation is the common name for a group of reactions that occur when carbohydrates are exposed to high temperatures with no amino groups involved. This reaction is influenced by $\mathrm{pH}$, impurities (salts) and sucrose concentration of the solution (Clarke, Edye, \& Eggleston, 1997; Eggleston \& Vercellotti, 2000; Lowary \& Richards, 1988; Mauch, 1971; Richards, 1986; Vukov, 1965). When highly concentrated sucrose solutions are heated at high temperatures and neutral $\mathrm{pH}$, a lag phase on sucrose degradation occurs (Clarke et al., 1997; Eggleston, Trask-Morrel, \& Vercellotti, 1996; Lowary \& Richards, 1988; Richards, 1986). Such solutions are of special importance in confectionery products or sugar boiling during white sugar production. The first reaction step in the caramelisation reaction is sucrose hydrolysis leading to glucose and fructose production (Clarke et al., 1997; Eggleston et al., 1996; Lowary \& Richards, 1988; Mauch, 1971; Richards, 1986). Further degradation of these products is responsible for the formation of other compounds, with special preponderance to the thermodynamically stable 5-hydroxymethylfurfural (HMF) (Antal, Mok, \& Richards, 1990; Clarke et al., 1997; Eggleston et al., 1996; Kroh, 1994; Lowary \& Richards, 1988; Mauch, 1971).

The typical brown colour developed during caramelisation is attributed to the production of polymeric products during the reaction course and HMF and furfural 
are pointed out as precursors of such polymers (Kroh, 1994).

Colour changes together with HMF content have been studied for numerous food systems, such as fruit juices and purees (Bozkurt, Gogus, \& Eren, 1999; Carabasa, Ibarz, Garza, \& Barbosa-Canovas, 1998; Garza, Ibarz, Pagan, \& Giner, 1999; Ibarz, Pagan, \& Garza, 2000; Kadakal \& Nas, 2003; Rattanathanalerk, Chiewchan, \& Srichumpoung, 2005; Tosun, 2004), dairy products (CaisSokolinska, Pikul, Dankow, \& Wojtowski, 2005; Kumar \& Mishra, 2004; Patel, Gandhi, Singh, \& Patil, 1996), baked goods (Ramirez-Jimenez, Garcia-Villanova, \& Guerra-Hernandez, 2000, 2001), infant foods (FernandezArtigas, Guerra-Hernandez, \& Garcia-Villanova, 1999; Guerra-Hernandez, Leon, Corzo, Garcia-Villanova, \& Romera, 2002; Ramirez-Jimenez, Guerra-Hernandez, \& Garcia-Villanova, 2003), honey (Terrab, Gonzalez, Diez, \& Heredia, 2003) and model Maillard systems (CarabasaGiribet \& Ibarz-Ribas, 2000a, 2000b; Shen \& Wu, 2004). However, few studies try to correlate HMF content with colour development. Most of such studies only report the observation or not of a linear correlation between such factors (Burdurlu \& Karadeniz, 2003; Fallico, Arena, \& Zappala, 2003) and in even fewer cases the possibility of an exponential correlation is addressed (Ramirez-Jimenez, Guerra-Hernandez, \& Garcia-Villanova, 2000). To the authors' best knowledge, only one work approached the development of a mathematical model to describe such correlation and a power law was used (Lee \& Nagy, 1988).

The lag phase and autocatalytic behaviour observed during sucrose degradation in highly concentrated neutral solutions has been previously discussed and modelled using a modified Gompertz equation (Quintas, Brandão, \& Silva, 2007). Since sucrose hydrolysis is the first step of the caramelisation reaction, the lag phase observed on sucrose degradation of highly concentrated solutions is expected to be also observed in colour development monitoring. In fact, this lag phase (or induction period) has been observed in non-enzymatic browning of freeze dried acidic model systems containing sucrose (Karel \& Labuza, 1968; Labuza, Tannenbaum, \& Karel, 1970) and other carbohydratebased food model systems (Carabasa-Giribet \& IbarzRibas, 2000a, 2000b; Miao \& Roos, 2004).

This work aims at studying colour formation and investigating the relationship of caramelisation reaction extent with colour changes. To achieve that, (i) colour changes through the caramelisation reaction course were modelled and (ii) the effect of sucrose degradation and HMF production on colour development was studied. Experiments were carried out with concentrated sucrose solutions, where lag phase in sucrose degradation was previously observed $(16.32 \%(\mathrm{w} / \mathrm{w})$ water content $)$, treated at temperatures ranging from 100 to $160{ }^{\circ} \mathrm{C}$, for different times. The kinetic behaviour was mathematically described and models were proposed to express colour dependence on HMF content. The temperature effect on both kinetic parameters and colour/HMF behaviour was investigated.

\section{Materials and methods}

\section{Experimental procedures \\ Sample preparation}

Sucrose solutions of $83 \%(w / w)$ were prepared by weighing commercial sucrose and adding distilled water in the desired proportion. The mixture was then heated in a microwave oven (medium power) for short periods ( $1 \mathrm{~min}$ ute), stirred intermittently until complete sucrose dissolution (Braga da Cruz, MacInnes, Oliveira, \& Malcata, 2002).

A Karl Fisher coulometric determination $(684 \mathrm{~K}$ coulometer, Metrohm, Switzerland) was used to measure the real moisture content of concentrated sucrose solutions. At least three different batches were prepared and each batch was analysed three times. The 95\% Standard Error (SE) of the sample water content was calculated. Results indicated a $16.32 \pm 0.82(\% \mathrm{w} / \mathrm{w})$ water content.

The solutions were poured into Thermal Death Time (TDT) cans, $6 \mathrm{~cm}$ diameter and $0.8 \mathrm{~cm}$ height $(208 \times$ 0.06 , American National Can, USA), sealed under vacuum, and processed isothermally at $100,120,140$, and $160^{\circ} \mathrm{C}$ in an oil bath (polyethelene glycol 400, Clariant) for different times.

\section{Colour measurement}

Samples were poured into a clear glass petri dish and colour parameters were determined using a tristimulus colorimeter (Minolta Chroma Meter CR300, Japan), programmed to use illuminant $\mathrm{C}$ as light source and the $2^{\circ}$ observer for colour interpretation. Results were calculated by the equipment into the Hunter Lab colour scale. In this scale, $L$ ranges from 0 (black) to 100 (white), $a$ indicates degree of greenness (for negative $a$ values) and degree of redness (for positive $a$ results), $\mathrm{b}$ axis also ranges from negative to positive values indicating, respectively, degree of blueness to yellowness. The $L_{0}, a_{0}$ e $b_{0}$ were calculated from non-heat-treated samples ( 8 measurements). Colour changes were assessed using $L / L_{0}$ and $\mathrm{TCD}_{\mathrm{H}}$ (i.e., $\mathrm{TCD}$ evaluated on Hunter colour space) parameters.

\section{Determination of 5-hydroxymethylfurfura Icontent}

HMF content of the studied solutions was determined using High Pressure Liquid Chromatography (HPLC). Standard solutions were prepared from HMF (pure, Fluka). Both samples and standard solutions were filtered $(0.45 \mu \mathrm{m})$ and analysed in a HPLC system (Jasco, Japan), equipped with a PU-1580 pump and an AS-1555 injector. The column was a Waters Spherisorb ${ }^{\circledR} \mathrm{S} 5$ ODS2 $\mathrm{C}_{18}$ and the mobile phase, acetonitrile (Isocratic Grade, Lichrosolv, Merck)/water (70:30), was running at $1.2 \mathrm{ml} / \mathrm{min}$. Peaks were detected using a UV detector (UV-1575, Jasco) set at $284 \mathrm{~nm}$ and analysed using Jasco-Borwin software v.1.50 (JMBS Developments, Fontaine, France). The HMF content was expressed in $g_{\mathrm{HMF}} / g_{\text {solution }}$. 


\section{Modelling procedures}

\section{Colour kinetics and temperature effect}

Lag and exponential phases of colour development may be described using the original Gompertz equation (Gompertz, 1825; Zwietering, Jöngenburger, Rombouts, \& Riet, 1990). This original function describes a growth tendency, which can be modified and reparameterised to parameters with physical meaning for describing any autocatalytic kinetic behaviour (Gil, Brandao, \& Silva, 2006; Quintas et al., 2007; Zwietering et al., 1990).

$C=\alpha \exp [-\exp (\beta-\chi t)]$

where $C$ is the studied colour parameter (i.e. $L, a, b$ or other) at any given reaction time, $t$, and $\alpha, \beta$, and $\chi$ are model parameters.

This model describes a growth tendency similar to the observed for $\mathrm{TCD}_{\mathrm{H}}$. For a decrease behaviour, such as the one observed for $L / L_{0}$, Eq. (2) can be modified as follows:

$C=1-\alpha \exp [-\exp (\beta-\chi t)]$

These equations can be reparameterised, calculating: a maximum reaction rate, $k_{\max }$ (determined by the slope of the steepest tangent to the exponential phase), and a lag time, $\lambda$ (calculated by the interception of the asymptot with the extrapolated tangent line). The equilibrium may be described using the $\alpha$ parameter, which represents the function asymptotic value when $t \rightarrow \infty$ (being $\beta$ such that, at $t=0, C \rightarrow 0$ in the original Gompertz equation (2)). Eqs. (3) and (2) can then be written as, respectively:

$$
\begin{aligned}
& \frac{L}{L_{0}}=1-\alpha \exp \left\{-\exp \left[\frac{k_{\max } e}{\alpha}(\lambda-t)+1\right]\right\} \\
& \mathrm{TCD}_{\mathrm{H}}=\alpha \exp \left\{-\exp \left[\frac{k_{\max } e}{\alpha}(\lambda-t)+1\right]\right\}
\end{aligned}
$$

The temperature effect on food reaction kinetics is often translated into a dependence of the kinetic parameters. This dependence has been widely studied and can be generally expressed with an Arrhenius type equation, using a finite reference temperature (Cohen, Birk, Mannheim, \& Saguy, 1994; Haralampu, Saguy, \& Karel, 1985; Peleg, 1992; van Boekel, 1996):

$p=p_{\text {ref }} \exp \left(-\frac{E_{\mathrm{a}}}{R}\left(\frac{1}{T}-\frac{1}{T_{\text {ref }}}\right)\right)$

where $p$ is a kinetic parameter, $E_{\mathrm{a}}$ is activation energy, $p_{\text {ref }}$ the kinetic parameter at finite reference temperature, $T_{\text {ref }}$, and $R$ the universal gas constant. $T_{\text {ref }}$ should correspond to the middle temperature of the experimental range, thus minimizing the correlation between parameters and the confidence intervals (Cohen et al., 1994; van Boekel, 1996).

\subsubsection{Non-linear regression analysis}

The equations mentioned along the text were fitted to experimental data by non-linear regression analysis, using STATISTICA $^{\mathrm{TM}}$ v 6.0 (Statsoft. Inc, USA) package. The
Levenberg-Marquadt algorithm for the least squares function minimisation was used. The statistical indicators of the quality of the regression and estimates precision, coefficient of determination $\left(R^{2}\right)$, the mean square error (MSE, i.e. the sum of squares of residuals divided by the corresponding degrees of freedom) and the $95 \%$ Standard Error of the parameters (SE), were obtained directly from the software. The precision of the estimated parameters was also evaluated by the Standardised Half Width (SHW), which was defined as the ratio between the 95\% Standard Error and the value of the estimate. Quality of regression was mainly assessed by visual inspection of residuals randomness and normality.

The measured response precision was evaluated by calculating the $95 \%$ inference band. The following expression is the linear approximation of the $95 \%$ inference band of a non-linear model (Bates \& Watts, 1988):

$C=\hat{C} \pm \sqrt{\operatorname{MSE}} \sqrt{v^{\mathrm{T}}\left(V^{\mathrm{T}} V\right)^{-1}} v \sqrt{P F_{(\mathrm{P}, \mathrm{N}-\mathrm{P}, 0.05)}}$

where $\hat{C}$ is the colour parameter estimated by the model, $\left(V^{\mathrm{T}} V\right)^{-1}$ is the variance-covariance matrix, $v$ is the parameters derivative vector, $P$ the number of estimated parameters, $N$ is experimental data points, and $F_{(\mathrm{P}, \mathrm{N}-\mathrm{P}, 0.05)}$ is the upper $5 \%$ of the quantile for Fisher distribution with $\mathrm{P}$ and N-P degrees of freedom.

\section{Results and discussion}

\section{Colour kinetics and temperature effect}

As expected, colour parameters changed with reaction extent. This change was evident in the responses $L / L_{0}$ and $\mathrm{TCD}_{\mathrm{H}}$ with time. In both cases, a lag phase was observed followed by an exponential phase and a final equilibrium value could be identified. There was a clear darkening of heat-treated sucrose solutions, evaluated by a decrease in the $L / L_{0}$ value, and a significant development of colour expressed through the increase of $\mathrm{TCD}_{\mathrm{H}}$ (Fig. 1).

The equilibrium value observed for the colour parameter is a rare observation in food quality factors degradation, which usually follow a zero or first-order kinetics (Villota \& Hawkes, 1992). However, such phenomenon has been previously observed for colour development reactions and in these cases a fractional conversion model has been reported (Ávila \& Silva, 1999; Garza et al., 1999; Ibarz et al., 2000; Silva \& Silva, 1999). This observed equilibrium for colour parameters may be due to the contribution of several different food components and their interactions.

These observed tendencies were described by modified and reparameterised Gompertz equations and results from fitting Eqs. (4) and (5) to, respectively, $L / L_{0}$ and $\mathrm{TCD}_{\mathrm{H}}$ experimental data are presented in Table 1. In both cases, residuals inspection and MSE (which is an indication of experimental error) indicated a good regression procedure. $\alpha$ and $k_{\max }$ parameters where estimated with acceptable 

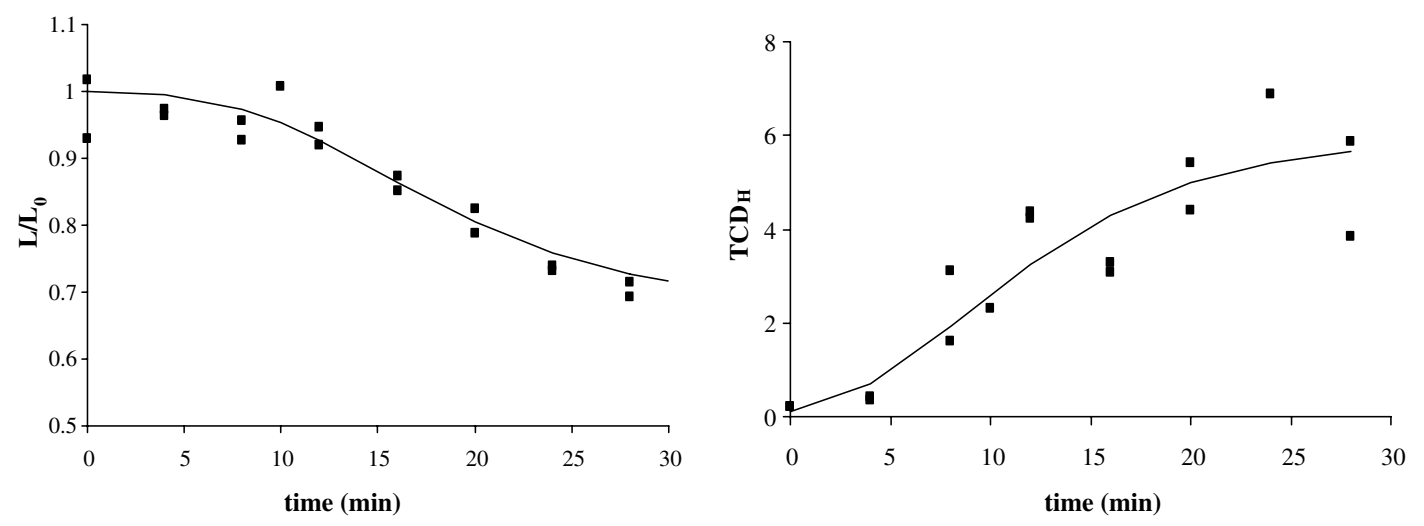

Fig. 1. Typical experimental behaviour observed (squares) and one-step model fitting result (lines), for both $L / L_{0}$ and $\mathrm{TCD}_{\mathrm{H}}$. Example is for isothermal experiments at $160^{\circ} \mathrm{C}$.

precision - SHW varied from 9 to $81 \%$ (with the exception of $L / L_{0}$ at $100^{\circ} \mathrm{C}$, which can be attributed to difficulties in experimental handling of the solutions and extremely large experimental times). Since $\mathrm{TCD}_{\mathrm{H}}$ behaviour is similar to the original Gompertz equation description, the estimated $\alpha$ represents the asymptotic value, i.e. the $\mathrm{TCD}_{\mathrm{H}}$ equilibrium value. However, in $L / L_{0}$ description and due to modification prior to reparameterisation, $\alpha$ represents the difference between the initial $L / L_{0}$ value $(\rightarrow 1)$ and equilibrium. The lag parameter $(\lambda)$ was estimated with less precision, with SHW varying from $32 \%$ to $256 \%$. Such decrease in precision of the lag parameter has been previously observed in modified and reparameterised Gompertz fitting to sucrose degradation data (Quintas et al., 2007). Moreover, $\lambda$ was similar for both colour parameters, which is probably due to the fact that $\lambda$ represents the "delay" in the caramelisation reaction.

To evaluate the significance of the description of the above models, the $95 \%$ inference band for the $\mathrm{TCD}_{\mathrm{H}}$ response with time at each temperature was calculated (Fig. 2). As it can be observed, estimated $\mathrm{TCD}_{\mathrm{H}}$ may lie in a considerably large interval. This problem can be circumvented by a more convenient and proper choice of sampling times through suitable experimental design (Brandão, 2004).

Concerning the effect of temperature on colour development, an Arrhenius type dependency was found for $k_{\max }$ and $\lambda$ of both cases. However, equilibrium (here evaluated by $\alpha$ estimate) was independent of temperature for $L / L_{0}$, and varied linearly for $\mathrm{TCD}_{\mathrm{H}}$. This is an indication that processing temperature does not affect the lightness of the final product, but influences the final colour difference from initial solution.

To study the influence of temperature in colour development reaction, the observed temperature dependence of the kinetic parameters $\alpha, k_{\max }$ and $\lambda$ was embedded in the two Eqs. (4) and (5) that were fitted to experimental data $\left(L / L_{0}\right.$ and $\mathrm{TCD}_{\mathrm{H}}$, respectively) at all temperatures: one-step model fitting (Arabshahi \& Lund, 1985; Cohen \& Saguy, 1985; Haralampu et al., 1985; Lund, 1983). The results from the regressions are presented in Table 2 and the adequacy of models description can be also observed in Fig. 1.

\section{Colour development vs sucrose degradation}

Previous studies showed an autocatalytic behaviour of sucrose thermal degradation, under the same reaction conditions of this work, due to both (i) $\mathrm{pH}$ drop during the reaction and (ii) increase of solution's molecular mobility (Quintas et al., 2007). To investigate the relationship between sucrose degradation and colour development, the estimated lag times and maximum reaction rates for sucrose degradation (in literature) and colour development (obtained in this work) were compared (Fig. 3). It can be observed that estimated lag times for both $L / L_{0}$ and $\mathrm{TCD}_{\mathrm{H}}$ coincide with estimated lag times for sucrose degradation. This is not at all unexpected, since colour develops with the reaction, which is not occurring before sucrose hydrolysis.

Regarding maximum reaction rates $\left(k_{\max }\right)$, sucrose degradation's is significantly higher than the darkening reaction (evaluated with $L / L_{0}$ parameter) rate, indicating that darkening may be related with the production of compounds formed later in the caramelisation reaction, as described in literature (Kroh, 1994). However, the total colour difference rate, although with higher estimates, is not significantly different from sucrose degradation rate. This may be indicative that other colour characteristics may be related with sucrose hydrolysis.

\section{Predicting colour changes with HMF content}

It is well known that HMF is a precursor of coloured compounds in the caramelisation reaction (Kroh, 1994). The contribution of HMF content to the observed colour changes was investigated on the basis of experimental data and fitting procedures. Based on visual inspection of experimental data, models were proposed and fitted to data; regression quality was then assessed by evaluation of residuals randomness and normality. Lightness 

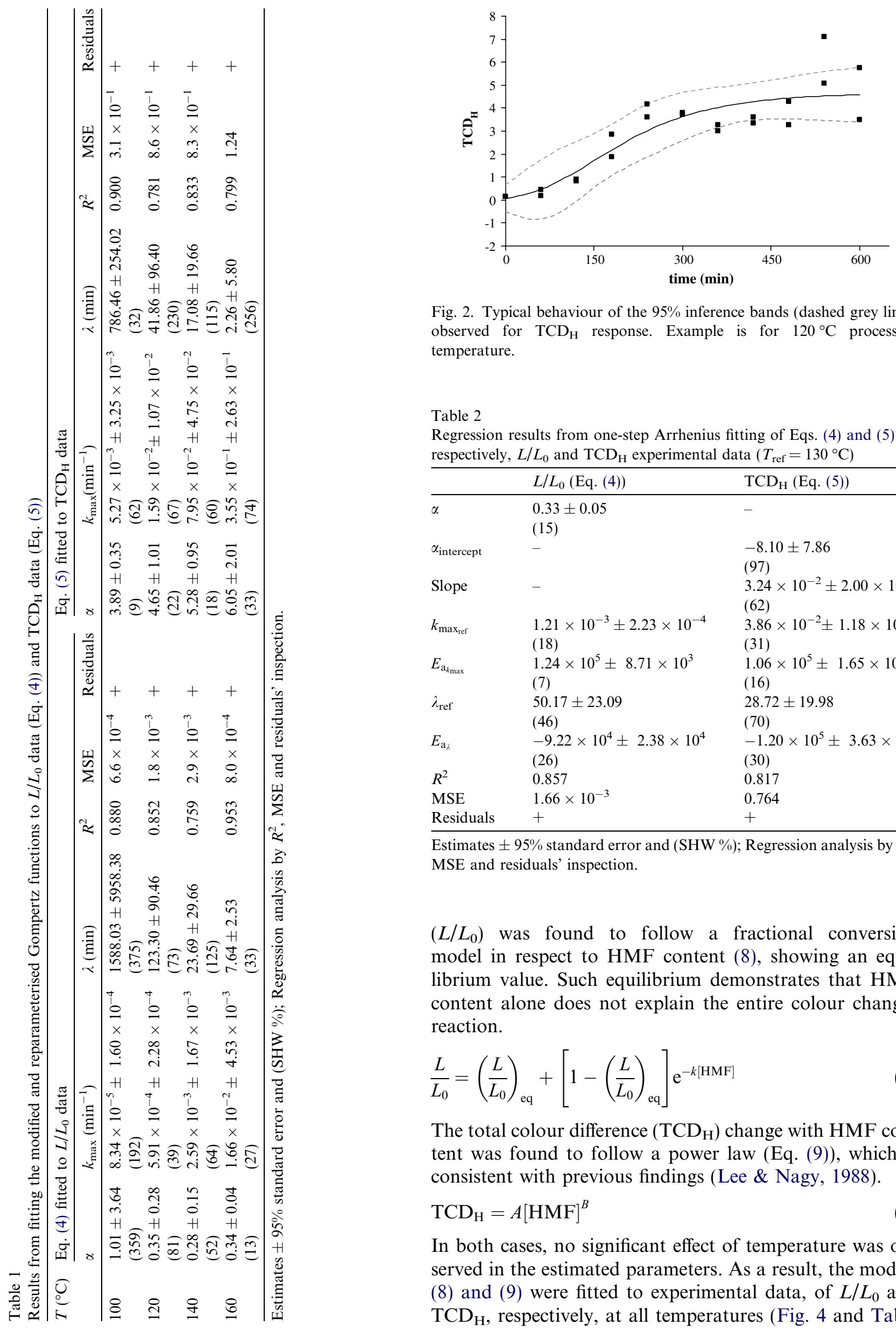

Fig. 2. Typical behaviour of the $95 \%$ inference bands (dashed grey lines) observed for $\mathrm{TCD}_{\mathrm{H}}$ response. Example is for $120^{\circ} \mathrm{C}$ processing temperature.

Table 2

Regression results from one-step Arrhenius fitting of Eqs. (4) and (5) to, respectively, $L / L_{0}$ and $\mathrm{TCD}_{\mathrm{H}}$ experimental data $\left(T_{\text {ref }}=130^{\circ} \mathrm{C}\right)$

\begin{tabular}{lll}
\hline & $L / L_{0}$ (Eq. (4)) & TCD $_{\mathrm{H}}$ (Eq. (5)) \\
\hline$\alpha$ & $0.33 \pm 0.05$ & - \\
& $(15)$ & $-8.10 \pm 7.86$ \\
$\alpha_{\text {intercept }}$ & - & $(97)$ \\
& & $3.24 \times 10^{-2} \pm 2.00 \times 10^{-2}$ \\
Slope & - & $(62)$ \\
& & $3.86 \times 10^{-2} \pm 1.18 \times 10^{-2}$ \\
$k_{\text {max }_{\text {ref }}}$ & $1.21 \times 10^{-3} \pm 2.23 \times 10^{-4}$ & $(31)$ \\
$E_{\mathrm{a}_{k_{\max }}}$ & $(18)$ & $1.06 \times 10^{5} \pm 1.65 \times 10^{4}$ \\
$\lambda_{\text {ref }}$ & $1.24 \times 10^{5} \pm 8.71 \times 10^{3}$ & $(16)$ \\
& $(7)$ & $28.72 \pm 19.98$ \\
$E_{\mathrm{a}_{\lambda}}$ & $(40.17 \pm 23.09$ & $(70)$ \\
$R^{2}$ & $-9.22 \times 10^{4} \pm 2.38 \times 10^{4}$ & $-1.20 \times 10^{5} \pm 3.63 \times 10^{4}$ \\
MSE & $(26)$ & $(30)$ \\
Residuals & 0.857 & 0.817 \\
\hline Estimates & $1.66 \times 10^{-3}$ & 0.764 \\
& + & +
\end{tabular}

Estimates $\pm 95 \%$ standard error and (SHW \%); Regression analysis by $R^{2}$, MSE and residuals' inspection.

$\left(L / L_{0}\right)$ was found to follow a fractional conversion model in respect to HMF content (8), showing an equilibrium value. Such equilibrium demonstrates that HMF content alone does not explain the entire colour changes reaction.

$\frac{L}{L_{0}}=\left(\frac{L}{L_{0}}\right)_{\mathrm{eq}}+\left[1-\left(\frac{L}{L_{0}}\right)_{\mathrm{eq}}\right] \mathrm{e}^{-k[\mathrm{HMF}]}$

The total colour difference $\left(\mathrm{TCD}_{\mathrm{H}}\right)$ change with HMF content was found to follow a power law (Eq. (9)), which is consistent with previous findings (Lee \& Nagy, 1988).

$\mathrm{TCD}_{\mathrm{H}}=A[\mathrm{HMF}]^{B}$

In both cases, no significant effect of temperature was observed in the estimated parameters. As a result, the models (8) and (9) were fitted to experimental data, of $L / L_{0}$ and $\mathrm{TCD}_{\mathrm{H}}$, respectively, at all temperatures (Fig. 4 and Table 

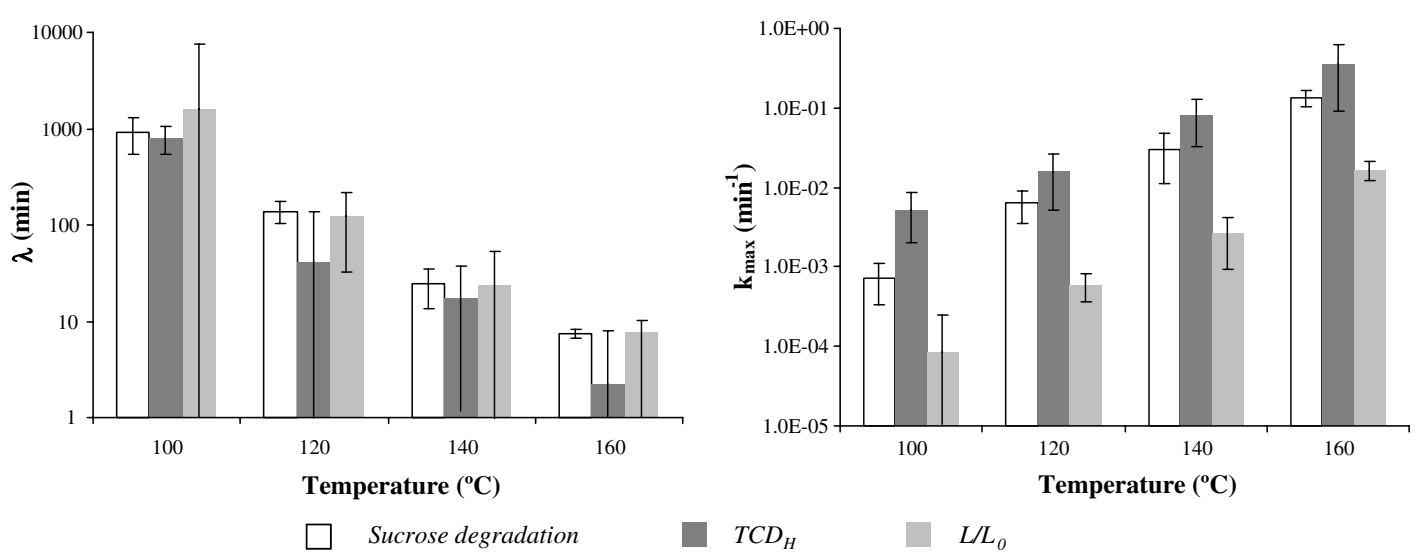

Fig. 3. Comparison of sucrose degradation $\lambda$ and $k_{\max }$ parameters (from Quintas et al., 2007) with estimated parameters for TCD ${ }_{\mathrm{H}}$ and $L / L_{0}$ description. Bars indicate the $95 \%$ confidence limits.
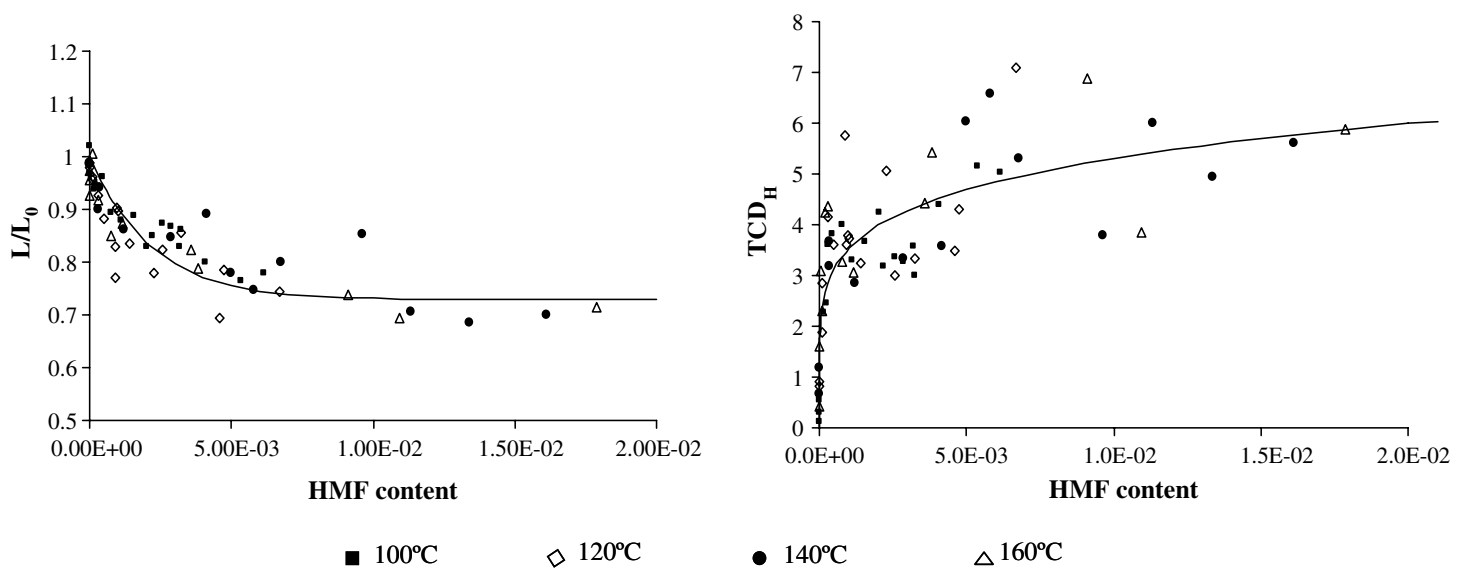

Fig. 4. Dependence of $L / L_{0}$ and $\mathrm{TCD}_{\mathrm{H}}$ on HMF content. Models (8) and (9) fitted to experimental data at different temperatures.

Table 3

Regression results from Eqs. (8) and (9) to, respectively, $L / L_{0}$ and $\mathrm{TCD}_{\mathrm{H}}$ experimental data at all temperatures

\begin{tabular}{lll}
\hline & $L / L_{0}$ (Eq. (8)) & TCD $_{\mathrm{H}}$ (Eq. (9)) \\
\hline$A$ & - & $11.94 \pm 3.04$ \\
$B$ & - & $(25)$ \\
& & $0.176 \pm 0.042$ \\
$\left(L / L_{0}\right)_{\mathrm{eq}}$ & $0.729 \pm 0.025$ & $(24)$ \\
$k$ & $(3)$ & - \\
& $463.72 \pm 132.03$ & - \\
$R^{2}$ & $(28)$ & 0.661 \\
MSE & 0.765 & $9.02 \times 10^{-1}$ \\
\hline
\end{tabular}

Estimates $\pm 95 \%$ standard error and (SHW \%); Regression analysis by $R^{2}$ and MSE.

3). Experimental data was successfully described by the proposed models. The observed equilibrium value in the colour parameters, prove that HMF content alone is not able to explain colour changes throughout caramelisation reaction.

\section{Conclusion}

Colour changes due to caramelisation reaction were evaluated by $L / L_{0}$ and $\mathrm{TCD}_{\mathrm{H}}$. An autocatalytic behaviour was observed, similar to sucrose degradation kinetics under the same conditions. The Gompertz model was successfully modified and reparameterised to describe kinetic behaviour and the temperature effect on the reaction was described by Arrhenius type dependency. Estimated colour kinetic parameters where related with literature sucrose degradation parameters: (i) the lag phase was of the same magnitude in both phenomena; (ii) $k_{\max }$ comparison showed different reaction rates, indicating that not only sucrose contributes to colour alterations. The contribution of HMF content to colour changes was studied and a fractional conversion and a power law models were found to describe $L / L_{0}$ and $\mathrm{TCD}_{\mathrm{H}}$ experimental data, respectively.

Knowledge of colour change kinetics is important for industrial process design and control. Furthermore, this work reinforces the use of sigmoid functions to describe autocatalytic behaviour and emphasizes the importance of inference bands on model's predicting ability. Under- 
standing the relationship of colour with reaction products may help in clarifying the contribution of different substances to non-enzymatic browning. This research is a contribution to that objective. In the long run, such results can be used by industry for colour design in new products development.

\section{Acknowledgements}

The present work was supported by the project POCTI/ EQU/49194/02 "Development of a computational tool to predict the composition of new "sugar free" sweet formulations for traditional Portuguese pastry industry - SWEETCOM", financed by Fundação para a Ciência e a Tecnologia (FCT). Authors M. Quintas and T.R.S. Brandão acknowledge FCT for grants PraxisXXI/BD/20057/ 99 and SFRH/BPD/11580/2002, respectively.

\section{References}

Antal, M. J., Jr., Mok, W. S. L., \& Richards, G. N. (1990). Mechanism of formation of 5-(hydroxymethyl)-2-furaldehyde from -fructose and sucrose. Carbohydrate Research, 199(1), 91-109.

Arabshahi, A., \& Lund, D. (1985). Considerations in calculating kinetic parameters from experimental data. Journal of Food Process and Engineering, 7(4), 239-251.

Ávila, I., \& Silva, C. L. M. (1999). Modelling kinetics of thermal degradation of colour in peach puree. Journal of Food Engineering, $39(2), 161-166$.

Baisier, W. M., \& Labuza, T. P. (1992). Maillard browning kinetics in a liquid model system. Journal of Agriculture and Food Chemistry, 40(5), 707-713.

Bates, D., \& Watts, D. (1988). Non-linear regression analysis and its applications. New York: John Wiley \& Sons, pp. 134-167.

Bell, L. N., White, K. L., \& Chen, Y. H. (1998). Maillard reaction in glassy low-moisture solids as affected by buffer type and concentration. Journal of Food Science, 63(5), 785-788.

BeMiller, J. N., \& Whistler, R. L. (1996). Carbohydrates. In O. R. Fennema (Ed.), Food chemistry (pp. 157-224). New York: Marcel Dekker, Inc..

Bozkurt, H., Gogus, F., \& Eren, S. (1999). Nonenzymic browning reactions in boiled grape juice and its models during storage. Food Chemistry, 64(1), 89-93.

Braga da Cruz, I., MacInnes, W. M., Oliveira, J. C., \& Malcata, F. X. (2002). Supplemented state diagram for sucrose from dynamic mechanical thermal analysis. In H. Levine (Ed.), Amorphous food and pharmaceutical systems (pp. 59-70). Cambridge: The Royal Society of Chemistry.

Brandão, T. R. S. (2004). Application of non-isothermal methods to the estimation of mass transfer parameters: analysis of the effect of experimental design and data analysis on the precision and accuracy of the estimates - appendixes. College of Biotechnology. Porto, Catholic University of Portugal, D.1-D.16.

Bruijn, J. M., Stuijs, J. L. M., \& Bout-Dierderen, M. E. F. (1999). Sucrose degradation and color formation. Zuckerindustrie, 124(1), 28-33.

Buera, M. P., Chirifie, J., Resnik, S. L., \& Lozano, R. D. (1987a). Nonenzymatic browning in liquid model systems of high water activity: Kinetics of color changes due to caramelization of various single sugars. Journal of Food Science, 52(4), 1059-1062.

Buera, M. P., Chirifie, J., Resnik, S. L., \& Lozano, R. D. (1987b). Nonenzymatic browning in liquid model systems of high water activity: Kinetics of color changes due to reaction between glucose and glycine peptides. Journal of Food Science, 52(4), $1068-1070$.
Buera, M. P., Chirifie, J., Resnik, S. L., \& Wetzler, G. (1987). Nonenzymatic browning in liquid model systems of high water activity: Kinetics of color changes due to Maillard's reaction between different single sugars and glycine and comparison with caramelization browning. Journal of Food Science, 52(4), 1063-1067.

Burdurlu, H. S., \& Karadeniz, F. (2003). Effect of storage on nonenzymatic browning of apple juice concentrates. Food Chemistry, 80(1), 91-97.

Cais-Sokolinska, D., Pikul, J., Dankow, R., \& Wojtowski, J. (2005). Changes in some selected physico-chemical and sensory parameters of UHT milk during storage at different temperatures. MilchwissenschaftMilk Science International, 60(1), 37-40.

Cammerer, B., Wedzicha, B. L., \& Kroh, L. W. (1999). Nonenzymatic browning reactions of retro-aldol degradation products of carbohydrates. European Food Research and Technology, 209(3-4), 261-265.

Carabasa-Giribet, M., \& Ibarz-Ribas, A. (2000a). Kinetics of colour development in aqueous fructose systems at high temperatures. Journal of the Science of Food and Agriculture, 80(14), 2105-2113.

Carabasa-Giribet, M., \& Ibarz-Ribas, A. (2000b). Kinetics of colour development in aqueous glucose systems at high temperatures. Journal of Food Engineering, 44(3), 181-189.

Carabasa, M., Ibarz, A., Garza, S., \& Barbosa-Canovas, G. V. (1998). Removal of dark compounds from clarified fruit juices by adsorption processes. Journal of Food Engineering, 37(1), 25-41.

Clarke, M. A., Edye, L. A., \& Eggleston, G. (1997). Sucrose decomposition in aqueous solution, and losses in sugar manufacture and refining. Advances in Carbohydrate Chemistry and Biochemistry, 52, 441-470.

Cohen, E., Birk, Y., Mannheim, C. H., \& Saguy, I. S. (1994). Kinetic parameter-estimation for quality change during continuous thermalprocessing of grapefruit juice. Journal of Food Science, 59(1), 155-158.

Cohen, E., \& Saguy, I. (1985). Statistical evaluation of Arrhenius model and its applicability in prediction of food quality losses. Journal of Food Processing and Preservation, 9(4), 273-290.

Eggleston, G., Trask-Morrel, B., \& Vercellotti, J. R. (1996). Use of differential scanning calorimetry and thermogravimetric analysis to characterize the thermal degradation of crystalline sucrose and dried sucrose-salt residues. Journal of Agricultural and Food Chemistry, 44(10), 3319-3325.

Eggleston, G., \& Vercellotti, J. R. (2000). Degradation of sucrose, glucose and fructose in concentrated aqueous solutions under constant $\mathrm{pH}$ conditions at elevated temperature. Journal of Carbohydrate Chemistry, 19(9), 1305-1318.

Fallico, B., Arena, E., \& Zappala, M. (2003). Roasting of hazelnuts. Role of oil in colour development and hydroxymethylfurfural formation. Food Chemistry, 81(4), 569-573.

Fernandez-Artigas, P., Guerra-Hernandez, E., \& Garcia-Villanova, B. (1999). Browning indicators in model systems and baby cereals. Journal of Agricultural and Food Chemistry, 47(7), 2872-2878.

Francis, F. J. (1995). Quality as influenced by color. Food Quality and Preference, 6(3), 149-155.

Garza, S., Ibarz, A., Pagan, J., \& Giner, J. (1999). Non-enzymatic browning in peach puree during heating. Food Research International, 32(5), 335-343.

Gil, M. M., Brandao, T. R. S., \& Silva, C. L. M. (2006). A modified Gompertz model to predict microbial inactivation under time-varying temperature conditions. Journal of Food Engineering, 76(1), 89-94.

Gompertz, B. (1825). On the nature of the function expressive of the law of human mortality, and on a new mode of determining the value of life contingencies. Philosophical Transactions of the Royal Society of London, 115, 513-585.

Guerra-Hernandez, E., Leon, C., Corzo, N., Garcia-Villanova, B., \& Romera, J. M. (2002). Chemical changes in powdered infant formulas during storage. International Journal of Dairy Technology, 55(4), 171-176.

Haralampu, S. G., Saguy, I. S., \& Karel, M. (1985). Estimation of Arrhenius model parameters using three least squares methods. Journal of Food Processing and Preservation, 9(3), 129-143. 
Hutchings, J. B. (1994). Food colour and appearance. Glasgow: Blackie Academic \& Professional, p. 513.

Ibarz, A., Pagan, J., \& Garza, S. (2000). Kinetic models of non-enzymatic browning in apple puree. Journal of the Science of Food and Agriculture, 80(8), 1162-1168.

Imming, R., Buczys, R., Lehnberger, A., \& Bliesener, K. M. (1996). A new approach to the kinetics of colour formation in concentrated carbohydrate solutions. Starch/Starke, 48(5), 163-166.

Kadakal, C., \& Nas, S. (2003). Effect of heat treatment and evaporation on patulin and some other properties of apple juice. Journal of the Science of Food and Agriculture, 83(9), 987-990.

Karel, M., \& Labuza, T. P. (1968). Nonenzymatic browning in model systems containing sucrose. Journal of Agriculture and Food Chemistry, 16(5), 717-719.

Kroh, L. W. (1994). Caramelisation in food and beverages. Food Chemistry, 51(4), 373-379.

Kumar, P., \& Mishra, H. N. (2004). Storage stability of mango soy fortified yoghurt powder in two different packaging materials: HDPP and ALP. Journal of Food Engineering, 65(4), 569-576.

Labuza, T. P., Tannenbaum, S. R., \& Karel, M. (1970). Water content and stability of low moisture and intermediate-moisture foods. Food Technology, 24(5), 543-548.

Lee, H. S., \& Nagy, S. (1988). Relationship of sugar degradation to detrimental changes in citrus juice quality. Food Technology, 42(10), 91-97.

Lievonen, S. M., Laaksonen, T. J., \& Roos, Y. H. (1998). Glass transition and reaction rates: Nonenzymatic browning in glassy and liquid systems. Journal of Agricultural and Food Chemistry, 46(7), 2778-2784.

Lowary, T. L., \& Richards, G. N. (1988). Effects of impurities on hydrolysis of sucrose in concentrated aqueous solutions. International Sugar Journal, 90(1077), 164-167.

Lund, D. B. (1983). Considerations in modeling food processes. Food Technology, 37(1), 92-94.

Mauch, W. (1971). Chemical properties of sucrose. Sugar Technology Reviews, 1, 239-290.

Miao, S., \& Roos, Y. H. (2004). Nonenzymatic browning kinetics of a carbohydrate-based low-moisture food system at temperatures applicable to spray drying. Journal of Agricultural and Food Chemistry, 52(16), 5250-5257.

Patel, A. A., Gandhi, H., Singh, S., \& Patil, G. R. (1996). Shelf-life modeling of sweetened condensed milk based on kinetics of Maillard browning. Journal of Food Processing and Preservation 20(6), 431-451.

Peleg, M. (1992). On the use of the WLF model in polymers and foods. Critical Reviews in Food Science and Nutrition, 32(1), 59-66.

Quintas, M., Brandão, T. R. S., \& Silva, C. L. M. (2007). Modelling autocatalytic behaviour of a food model system - sucrose thermal degradation at high concentrations. Journal of Food Engineering, 78(2), 537-545.

Ramirez-Jimenez, A., Garcia-Villanova, B., \& Guerra-Hernandez, E. (2000). Hydroxymethylfurfural and methylfurfural content of selected bakery products. Food Research International, 33(10), 833-838.

Ramirez-Jimenez, A., Garcia-Villanova, B., \& Guerra-Hernandez, E. (2001). Effect of toasting time on the browning of sliced bread. Journal of the Science of Food and Agriculture, 81(5), 513-518.

Ramirez-Jimenez, A., Guerra-Hernandez, E., \& Garcia-Villanova, B. (2000). Browning indicators in bread. Journal of Agricultural and Food Chemistry, 48(9), 4176-4181.

Ramirez-Jimenez, A., Guerra-Hernandez, E., \& Garcia-Villanova, B. (2003). Evolution of non-enzymatic browning during storage of infant rice cereal. Food Chemistry, 83(2), 219-225.

Rattanathanalerk, M., Chiewchan, N., \& Srichumpoung, W. (2005). Effect of thermal processing on the quality loss of pineapple juice. Journal of Food Engineering, 66(2), 259-265.

Reyes, F. G. R., Poocharoen, B., \& Wrolstad, R. E. (1982). Maillard browning reaction of sugar-glycine model systems - changes in sugar concentration, color and appearance. Journal of Food Science, 47(4), 1376-1377.

Richards, G. N. (1986). Initial steps in thermal degradation of sucrose. International Sugar Journal, 88(1052), 145-148.

Schebor, C., Buera, M. D., Karel, M., \& Chirife, J. (1999). Color formation due to non-enzymatic browning in amorphous, glassy, anhydrous, model systems. Food Chemistry, 65(4), 427-432.

Shen, S. C., \& Wu, J. S. B. (2004). Maillard browning in ethanolic solution. Journal of Food Science, 69(4), C273-C279.

Silva, F. M., \& Silva, C. L. M. (1999). Colour changes in thermally processed cupuacu (theobroma grandiflorum) puree: Critical times and kinetics modelling. International Journal of Food Science and Technology, 34(1), 87-94

Terrab, A., Gonzalez, A. G., Diez, M. J., \& Heredia, F. J. (2003). Characterisation of moroccan unifloral honeys using multivariate analysis. European Food Research and Technology, 218(1), 88-95.

Tosun, I. (2004). Color changes and 5-hydroxymethyl furfural formation in zile pekmezi during storage. Grasas Y Aceites, 55(3), 259-263.

van Boekel, M. A. J. S. (1996). Statistical aspects of kinetic modeling for food science problems. Journal of Food Science, 61(3), 447-485, 489.

Villota, R., \& Hawkes, J. G. (1992). Reaction kinetics in food systems. In D. R. Heldman \& D. B. Lund (Eds.), Handbook of food engineering (pp. 39-144). New York: Marcel Dekker, Inc..

Vukov, K. (1965). Kinetic aspects of sucrose hydrolysis. The International Sugar Journal, 67, 172-175.

Zwietering, M. H., Jöngenburger, I., Rombouts, F. M., \& Riet, K. V. t. (1990). Modeling of the bacterial growth curve. Applied and Environmental Microbiology, 56(6), 1875-1881. 